\title{
Differential modulation of nitric oxide synthases in aging: therapeutic opportunities
}

\section{Stefany B. A. Cau, Fernando S. Carneiro and Rita C. Tostes*}

Department of Pharmacology, Medical School of Ribeirao Preto, Ribeirao Preto, Brazil

Edited by:

Elisabet Vila, Autonomous University of Barcelona, Spain

\section{Reviewed by:}

Elisabet Vila, Autonomous University of Barcelona, Spain

Maria Dolores Herrera, Universidad de Sevilla, Spain

*Correspondence:

Rita C. Tostes, Department of Pharmacology, Medical School of Ribeirao Preto, University of Sao Paulo, Avenida Bandeirantes 3900 , Ribeirao Preto, Sao Paulo 14049-900, Brazil.

e-mail: rtostes@usp.br

\begin{abstract}
Vascular aging is the term that describes the structural and functional disturbances of the vasculature with advancing aging. The molecular mechanisms of aging-associated endothelial dysfunction are complex, but reduced nitric oxide (NO) bioavailability and altered vascular expression and activity of NO synthase (NOS) enzymes have been implicated as major players. Impaired vascular relaxation in aging has been attributed to reduced endothelial NOS (eNOS)-derived NO, while increased inducible NOS (iNOS) expression seems to account for nitrosative stress and disrupted vascular homeostasis. Although eNOS is considered the main source of NO in the vascular endothelium, neuronal NOS (nNOS) also contributes to endothelial cells-derived NO, a mechanism that is reduced in aging. Pharmacological modulation of NO generation and expression/activity of NOS isoforms may represent a therapeutic alternative to prevent the progression of cardiovascular diseases. Accordingly, this review will focus on drugs that modulate NO bioavailability, such as nitrite anions and NO-releasing non-steroidal anti-inflammatory drugs, hormones (dehydroepiandrosterone and estrogen), statins, resveratrol, and folic acid, since they may be useful to treat/to prevent aging-associated vascular dysfunction. The impact of these therapies on life quality in elderly and longevity will be discussed.
\end{abstract}

Keywords: aging, endothelial dysfunction, nitric oxide, nitric oxide synthases, uncoupled eNOS, statin, resveratrol, folic acid

\section{INTRODUCTION}

Many disorders emerge with advancing aging, and cardiovascular diseases (CVD) are a major cause of morbidity and mortality in the elderly ${ }^{1}$ (Lakatta and Levy, 2003). The term vascular aging encompasses all the structural and functional alterations in the blood vessels with progressive aging (Herrera et al., 2010). Both smooth muscle cells and intima layers are affected. These vascular changes lead to endothelial dysfunction, arterial stiffness in consequence of intense remodeling and calcification, impaired angiogenesis, greater susceptibility to vascular injury and atherosclerotic lesions (Lakatta and Levy, 2003; Herrera et al., 2010).

The mechanisms underlying vascular aging are complex and involve multiple pathways and factors, and a comprehensive description of all mechanisms is beyond the scope of this review. Excellent and very recent reviews on the topic are available

\footnotetext{
${ }^{1}$ According to the Department of Health Statistics and Health Information Systems, World Health Organization (WHO), (http://www.who.int/healthinfo/survey/ageingdefnolder/en/index.html), "Most developed world countries have accepted the chronological age of 65 years as a definition of "elderly" or older person," although this concept does not adapt well to every country or population. Chronological or "official" definitions of aging can differ widely from traditional or community definitions of when a person is older. In many parts of the developing world, chronological time has little or no importance in the meaning of old age, which is seen to begin at the point when active contribution is no longer possible. Since in this review the aging process is being looked from a biological perspective, which has its own dynamic, largely beyond human control, the chronological aging definition may seem more appropriate.
}

(Herrera et al., 2010; Seals et al., 2011; Toda, 2011). In this complex scenario, vascular function depends on the balanced production/bioavailability of nitric oxide (NO), which is maintained by the normal activity of endothelial nitric oxide synthase (eNOS). On the other hand, excessive amount of NO produced by inducible nitric oxide synthase (iNOS) up-regulation contributes to vascular dysfunction. Evidence obtained from experimental models indicates that decreased NO bioavailability as well as increased reactive nitrogen species (RNS) production contributes to aging-associated vascular dysfunction. These effects have been attributed to abnormal expression and activity of vascular NO synthase (NOS) isoforms. Accordingly, in this review, a very brief overview on $\mathrm{NO}$ signaling in cardiovascular aging is provided. The role of each NOS isoform on aging-associated vascular dysfunction is then discussed. The use of drugs that affect NO generation or modulate NOS expression/activity, including nitrite anions, NO-releasing non-steroidal anti-inflammatory drugs, statins, hormones (estrogen and dehydroepiandrosterone), resveratrol, and folic acid to prevent vascular dysfunction in elderly is also addressed.

\section{BRIEF BIOCHEMISTRY OF NO SIGNALING}

$\mathrm{NO}$ is a highly reactive signaling molecule, produced from the oxidation of the essential amino acid L-arginine by the NOS family (Figure 1). The eNOS and neuronal nitric oxide synthase (nNOS) isoforms are constitutively expressed in many tissues, including vessels and neurons (Melikian et al., 2009; Villanueva and Giulivi, 2010). Conversely, iNOS is expressed by vascular cells in response 


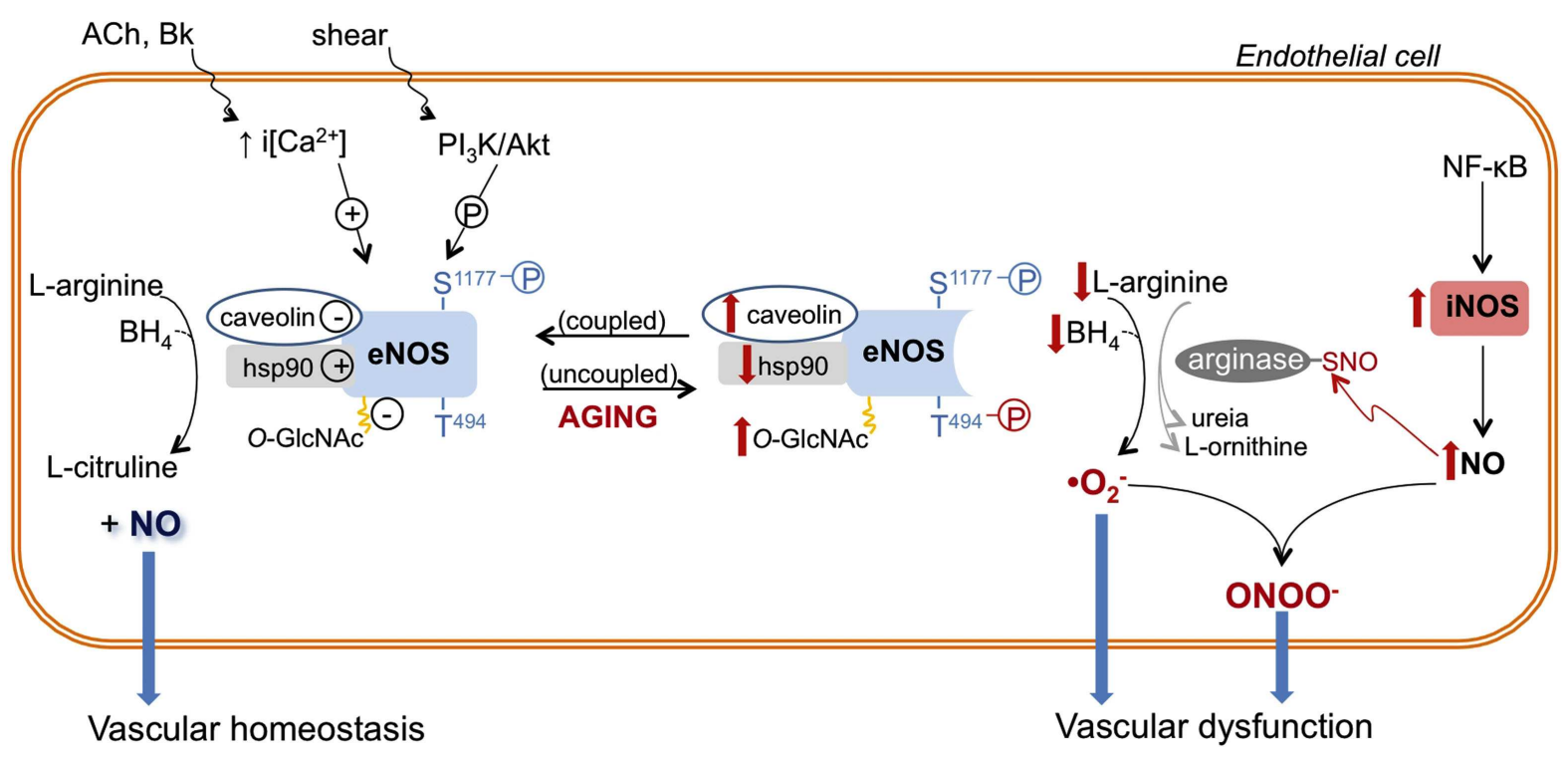

FIGURE 1 | Role of nitric oxide synthase (NOS) enzymes in endothelial function and aging-associated endothelial dysfunction. Endothelial (e)-NOS isoform converts l-arginine to nitric oxide (NO). eNOS activity is determined by intracellular calcium concentration $\left[i\left(\mathrm{Ca}^{2+}\right)\right]$ and/or its phosphorylation (P) state at different sites (e.g., eNOS is positively and negatively modulated by phosphorylation of serine $1177\left(\mathrm{~S}^{1177}\right)$ and threonine $494\left(T^{494}\right)$, respectively). In addition, eNOS activity is inhibited by its interaction with caveolin-1 and by O-GIcNAc modification, while eNOS association with heat shock protein 90 (hsp90) favors its activation. In endothelial aging, NO synthesis is compromised because eNOS activity is decreased due to increased expression and interaction with caveolin, reduced expression and association with hsp90, reduced phosphorylation of $S^{1177}$ and increased phosphorylation of $\mathrm{T}^{494}$. In addition, reduced availability of l-arginine and tetrahydrobiopterin $\left(\mathrm{BH}_{4}\right)$ induces eNOS uncoupling or changes the enzyme to a state that favors superoxide anion $\left(\bullet \mathrm{O}_{2}^{-}\right)$generation. In aged endothelial cells, up-regulated iNOS, which may be associated with NF-kB-induced vascular inflammation, produces high levels of NO. NO reacts with cysteine residues of proteins (arginase in this example), forming $S$-nitrosothiol (-SNO)-arginase, which increases arginase activity and I-arginine consumption. NO directly reacts with $\bullet \mathrm{O}_{2}^{-}$produced by uncoupled eNOS, and other vascular sources, generating the harmful reactive nitrogen specie peroxynitrite $\left(\mathrm{ONOO}^{-}\right)$, which contributes to vascular dysfunction. The aging-associated NOS alterations are depicted in red. ACh, acetylcholine; Bk, bradykinin; $\mathrm{Pl}_{3} \mathrm{~K}$, phosphoinositide-3-kinase. to chemokines and invading microorganisms (Hecker et al., 1999). eNOS and nNOS are calcium $\left(\mathrm{Ca}^{2+}\right)$-dependent, while iNOS is $\mathrm{Ca}^{2+}$-independent. Activation of specific receptors on endothelial cells (e.g., by bradykinin) increases the intracellular levels of $\mathrm{Ca}^{2+}$, which in turn, promotes eNOS activation and NO generation in the vascular system (Figure 1). NO production is also increased as a consequence of mechanical distension (shear stress) caused by blood flow on the vascular wall. NO generated by nNOS and iNOS is classically described as a neurotransmitter and a reactive molecule involved in bacterial killing, respectively. However, recent advances highlight the role of nNOS and iNOS in cardiovascular (dys)function (Melikian et al., 2009; Tsutsui et al., 2009) as well as in aging, as discussed later.

Nitrite and nitrate anions are known as end products of NO oxidation and reflect endogenous NOS activity (Dejam et al., 2004; Moncada and Higgs, 2006). However, nitrite can be reduced to NO by either hypoxia, tissue acidosis conditions, or by a number of enzymes. This makes nitrite an important complementary reservoir of NO in physiological conditions (Dejam et al., 2004).

NOS-produced NO reacts rapidly with amino acids residues, ions, and superoxide anion $\left(\bullet \mathrm{O}_{2}^{-}\right)$, a reactive oxygen species (ROS; Moncada and Higgs, 2006). The latter reaction is particularly important since, as a $\bullet \mathrm{O}_{2}^{-}$scavenger, $\mathrm{NO}$ becomes an antioxidant molecule at the same time that its bioavailability is reduced in the presence of high $\bullet \mathrm{O}_{2}^{-}$levels. Under conditions of L-arginine or tetrahydrobiopterin $\left(\mathrm{BH}_{4}\right)$ deficiency, NOS becomes a radical generating enzyme, a phenomenon referred as NOS uncoupling.

\section{EVIDENCE FOR A ROLE OF NO IN THE REGULATION OF LONGEVITY}

NO seems to be a key molecule to longevity and cardiovascular health. This concept was partially derived from studies addressing the cardiovascular function in mice that do not express at least one, a combination of two, or all NOS isozymes genes $\left(\mathrm{nNOS}^{-I-} ; \mathrm{iNOS}^{-I-} ; \mathrm{eNOS}^{-I-} ; \mathrm{n} / \mathrm{iNOSs}^{-I-} ; \mathrm{n} / \mathrm{eNOSs}^{-I-}\right.$; $\mathrm{i} / \mathrm{eNOSs}^{-/-} ; \mathrm{n} / \mathrm{i} / \mathrm{eNOSs}^{-/-}$; Tsutsui et al., 2009). Accordingly, the survival rate of 10 month-old triple NOS knockout mice is reduced by $\sim 80 \%$, mainly as a consequence of spontaneous myocardial infarction, coronary arteriosclerosis and mast cell infiltration in the coronary artery adventitia (Tsutsui et al., 2009). The role of each NOS is well established in some CVD. For instance, studies in mice models of atherogenesis demonstrated that eNOS and nNOS play protective roles, whereas iNOS is pro-atherosclerotic (Tsutsui et al., 2009). On the other hand, in particular conditions such as myocardial ischemia, iNOS up-regulation represents a compensatory molecular mechanism that protects myocardial cells from damage (Bolli, 2001). However, few studies have addressed whether chronic ablation of a specific NOS isoform affects lifespan. A role for eNOS in lifespan and spatial memory was suggested by a report showing that the survival rate of eNOS knockout mice was 
reduced by $50 \%$. Those mice also exhibit decreased exploratory behavior at 18-22 weeks of age when compared to age-matched controls (Dere et al., 2002). In addition, it has been reported that caloric restriction extends lifespan. However, this effect was strongly attenuated in eNOS knockout mice (Nisoli et al., 2005). This implicates eNOS-derived NO as one of the mechanisms by which caloric restriction extends lifespan.

In humans, an iNOS polymorphism is significantly more frequent in elderly hypertensive patients, indicating that abnormal iNOS-mediated NO formation may affect longevity in patients with moderate to severe hypertension (Glenn et al., 1999). In addition, cardiac overexpression of iNOS in mice leads to increased mortality, which is associated with gross ventricular dilation and hypertrophy, and sudden cardiac death due to bradyarrhythmia (Mungrue et al., 2002). Taken together, these data suggest that altered patterns of NO generation/turnover contribute to greater susceptibility to cardiovascular disorders in elderly, and that its regulation may decrease the risk of aging-associated diseases.

\section{NO GENERATION IN CARDIOVASCULAR AGING}

eNOS-derived NO is a fundamental mediator of vascular homeostasis (Moncada and Higgs, 2006). NO mediates vasodilation, inhibits leukocytes adhesion, and has antithrombotic and antiapoptotic effects. Several studies in human and animal models have shown that endothelium-dependent vasodilatation, a marker of endothelial function, progressively declines with age (Gerhard et al., 1996; Taddei et al., 2001; Muller-Delp et al., 2002; Blackwell et al., 2004; Sun et al., 2004; Delp et al., 2008; Rodriguez-Manas et al., 2009). Age-associated infirmities such as arterial hypertension, atherosclerosis, heart failure, and neurodegenerative diseases have endothelial dysfunction as a common vascular component. Reduced NO bioavailability in aging is a consistent feature in experimental and clinical studies. Vascular aging is accompanied by reduced eNOS expression/activity or augmented breakdown of NO by ROS. In addition, senescent endothelial cells phenotype shifts toward an inflammatory state, with up-regulation of adhesion molecules, cytokines, and chemokines (Ungvari et al., 2004). This phenotype favors platelet aggregation and inflammatory cell adhesion, which may progress to thrombotic and atherosclerotic events. The expression of pro-inflammatory enzymes, such as cyclooxygenase-2 (COX-2) and iNOS is induced by agingassociated endothelial dysfunction (Ungvari et al., 2004). COX-2derived lipid mediators can contribute to enhanced reactivity to vasoconstrictors (Briones et al., 2005; Novella et al., 2011). In addition, iNOS-derived high levels of NO can induce post-translational modification of proteins or react with ROS to produce RNS, which increases vasoconstrictor tonus in aged arteries.

The major molecular mechanisms of age-related endothelial dysfunction involve at least three NO-associated events: NO consumption by $\bullet \mathrm{O}_{2}^{-}$overproduction, reduced vascular antioxidant ability, and altered NOS enzymes expression/activity. Vascular oxidative stress also interferes with the actions of endothelial cellderived NO on vascular smooth muscle cells. Treatment of old animals with antioxidants or the exposure of arteries isolated from old mice to antioxidants restores endothelium-dependent dilation (Blackwell et al., 2004; Fleenor et al., 2011). The main vascular sources of ROS have been identified in aging: detaching mitochondria (Ungvari et al., 2010) and nicotinamide adenine dinucleotide phosphate (NADPH)-oxidase (NOx; Hamilton et al., 2001; Fleenor et al., 2011). As will be discussed, NOS can also act as a $\bullet \mathrm{O}_{2}^{-}$generator. Antioxidant enzymes such as superoxide dismutase, glutathione, and catalase are also down-regulated or exhibit decreased activity with aging (Sun et al., 2004; Lund et al., 2009; Denniss et al., 2011; Fleenor et al., 2011). The final consequence is an unbalanced ROS production and NO depletion in detriment of the antioxidant capacity.

Identifying the changes that each NOS isoform undergoes in vascular aging not only may help us to understand the natural adaptations of the NO pathways in the cardiovascular system with progressive aging, but may also provide novel targets for the treatment of aging-associated CVD.

\section{EFFECTS OF AGING ON VASCULAR NOS ISOFORMS EFFECTS OF AGING ON ENOS}

The role of aging on eNOS expression is controversial. Vascular eNOS expression with advancing aging has been shown to be either unchanged (Sun et al., 2004; Rodriguez-Manas et al., 2009; Yang et al., 2009), decreased (Challah et al., 1997; Yoon et al., 2010), or increased (Cernadas et al., 1998; Matz et al., 2000; van der Loo et al., 2000; Goettsch et al., 2001). Although data on eNOS expression are contradictory, it is well accepted that the activity of eNOS is reduced in aging (Cernadas et al., 1998; Chou et al., 1998; Smith et al., 2006a,b; Yoon et al., 2010). Particularly, eNOS activity is decreased by deficient availability of substrates or cofactors, subcellular location, protein-protein interactions, and post-translational modifications such as acylation, nitrosylation, O-GlcNAcylation, and phosphorylation (Dudzinski and Michel, 2007; Villanueva and Giulivi, 2010).

Plasma membrane-associated eNOS represents an immediately available agonist-sensitive pool of the enzyme (Dudzinski and Michel, 2007; Villanueva and Giulivi, 2010). In old rats, the amount of eNOS localized in the endothelial cell plasma membrane is reduced (Smith et al., 2006b). In addition, senescent endothelial cells in vitro display reduced NO synthesis accompanied by increased eNOS linkage with caveolin-1 (Yoon et al., 2010), a protein whose interaction with eNOS keeps the enzyme inactivated in a region of the plasma membrane named caveolae (Dudzinski and Michel, 2007). eNOS activity is extended by protein-protein association with heat shock protein 90 (hsp90), a chaperone involved in protein trafficking and folding (Dudzinski and Michel, 2007). Hsp90 expression and binding to eNOS is reduced in old endothelial cells (Smith et al., 2006b; Yoon et al., 2010). Together, these may partially explain the decreased eNOS activity and the reduced $\mathrm{NO}$-dependent vascular relaxation in elderly, as summarized in Figure 1.

In the presence of low intracellular $\mathrm{Ca}^{2+}$ levels, eNOS activity is maintained by phosphoinositide-3-kinase $\left(\mathrm{PI}_{3} \mathrm{~K}\right) /$ Akt-mediated phosphorylation of serine $1176\left(\mathrm{~S}^{1176}\right)$ or $1177\left(\mathrm{~S}^{1177}\right)$, in rat and human, respectively (Dudzinski and Michel, 2007). In contrast, phosphorylation of eNOS at threonine $494\left(\mathrm{~T}^{494}\right)$ negatively regulates its activity (Dudzinski and Michel, 2007). Reduced eNOS phosphorylation at $S^{1176} / S^{1177}$ and enhanced phosphorylation at $\mathrm{T}^{494}$ have been reported in endothelial cells from aged rats (Smith et al., 2006a) and senescent human endothelial cells in vitro (Yoon 
et al., 2010). Together, these data further support a role for reduced eNOS-produced NO in aging-associated vascular dysfunction.

Glycosylation with $O$-linked- $\beta$ - $N$-acetylglucosamine $(O-$ GlcNAc) is a post-translational modification of nuclear and cytoplasmic proteins. O-GlcNAc modification of eNOS seems to reduce eNOS phosphorylation at $\operatorname{Ser}^{1177}$ and, consequently, eNOS activity (Lima et al., 2009). The vascular content of O-GlcNAcmodified proteins is augmented in the vasculature of old animals (Fulop et al., 2008). Although the amount of vascular O-GlcNAcmodified eNOS in old animals has not yet been determined, it is possible that senescence-associated increased vascular $O$-GlcNAc levels can also contribute to eNOS dysfunction in aging.

In addition to its reduced NO-releasing ability, eNOS seems to play a deleterious role in aging. Accordingly, endothelium removal reverses the increased vascular $\bullet \mathrm{O}_{2}^{-}$production associated with aging (van der Loo et al., 2000). Furthermore, aging-associated vascular oxidative stress is partially reversed by pharmacological NOS inhibition (Kim et al., 2009; Yang et al., 2009), which suggests that eNOS contributes to $\bullet \mathrm{O}_{2}^{-}$generation. As already mentioned, uncoupled eNOS is a source of $\bullet \mathrm{O}_{2}^{-}$in the vasculature. In fact, the ratio of monomeric eNOS is increased in mesenteric arteries from aged rats, indicating that eNOS uncoupling is associated with increased $\bullet \mathrm{O}_{2}^{-}$production (Yang et al., 2009). In aging, eNOS uncoupling has been associated with reduced $\mathrm{BH}_{4}$ availability (Delp et al., 2008; Yang et al., 2009) rather than deficiency of L-arginine (Gates et al., 2007). Despite that, inhibition of arginase, an enzyme that degrades L-arginine, restores eNOS coupling in rat aortas (Kim et al., 2009). Moreover, addition of sepiapterin, a $\mathrm{BH}_{4}$ precursor, ameliorates vascular relaxation in conduit and resistance arteries from aged animals (Blackwell et al., 2004; Delp et al., 2008) and reverses eNOS uncoupling (Yang et al., 2009).

\section{EFFECT OF AGING ON INOS}

iNOS expression is consistently reported in aged vessels, mainly in the intima layer (Cernadas et al., 1998; Chou et al., 1998; Goettsch et al., 2001; Csiszar et al., 2002; Rodriguez-Manas et al., 2009; Tian et al., 2010). Pharmacological selective inhibition of iNOS prevented age-related decrease of cardiac function (Yang et al., 2004) and reversed impaired endothelium-dependent vasorelaxation in old rats (Tian et al., 2010) and in elder subjects (RodriguezManas et al., 2009). These exciting data reveal a new pathological mechanism involving iNOS in the abnormal constrictor vascular tone associated with aging. This is also reinforced by a recent report demonstrating iNOS up-regulation in microvessels of hypertensive subjects, and an impressive restoration of endothelium-dependent vasodilation by a selective iNOS inhibitor in hypertensive patients (Smith et al., 2011).

The mechanism of iNOS-induced vascular dysfunction in aging is not completely elucidated. Aging-associated iNOS upregulation is accompanied by RNS peroxynitrite $\left(\mathrm{ONOO}^{-}\right)$production (van der Loo et al., 2000), due to the reaction of NO with $\bullet \mathrm{O}_{2}^{-}$, which is facilitated in the pro-oxidant environment of aged arteries. $\mathrm{ONOO}^{-}$is a potent and harmful molecule to cellular lipids, genetic material, and proteins (Peluffo and Radi, 2007). Intense immnunostaining for nitrotyrosine, a marker of protein nitration by $\mathrm{ONOO}^{-}$(Peluffo and Radi, 2007), is found in aged vessels (Csiszar et al., 2002; Rodriguez-Manas et al., 2009; Tian et al., 2010). Furthermore, a pharmacological scavenger of $\mathrm{ONOO}^{-}$reversed the reduced endothelium-dependent dilation of arteries from old rats (van der Loo et al., 2000), implicating $\mathrm{ONOO}^{-}$in aging-associated endothelial dysfunction (Figure 1).

The amount of NO produced by iNOS is substantially greater than that produced by the constitutive isoforms, and NO itself may act as a cytotoxic agent and induce tissue damage (Hecker et al., 1999; Moncada and Higgs, 2006). The reaction between NO with cysteine residues of target proteins forming $S$-nitrosothiol (SNO) is denominated S-nitrosylation, and it modifies protein function (Moncada and Higgs, 2006). Arginase is a target protein for S-nitrosylation, and this post-translational modification increases the enzyme activity. Increased S-nitrosylation of arginase has been implicated in the decreased NO production and reduced endothelium-dependent relaxation in aortas from old rats (Santhanam et al., 2007). Interestingly, pharmacological inhibition of iNOS abrogated arginase S-nitrosylation and restored endothelium-dependent vasodilation (Santhanam et al., 2007), indicating that increased arginase activity depends on iNOS (Figure 1).

\section{EFFECTS OF AGING ON nNOS}

Although the regulatory roles of eNOS and iNOS in vascular aging have been studied, just a small amount of information on the contribution of nNOS to aging-associated vascular dysfunction is available. In addition, there is limited knowledge on how nNOS modulates vascular tone (Melikian et al., 2009).

Electrical stimulation of endothelium-denuded small arteries causes $\alpha$-adrenergic vasoconstriction, which is attenuated by nNOS. However, this negative modulatory effect by nNOS is significantly impaired in old rats (Ferrer and Balfagon, 2001). Furthermore, old hypertensive rats exhibit just a minor increase of vasoconstriction after pre-incubation with a selective nNOS inhibitor (Ferrer et al., 2003). These findings suggest that nNOS-derived $\mathrm{NO}$ in perivascular nitrergic innervation modulates microvascular tone by reducing $\alpha$-adrenergic vasoconstriction and that its absence may account for the abnormal vasoconstrictor tone in aged arterioles (Ferrer and Balfagon, 2001; Ferrer et al., 2003). Of importance, more studies on nNOS function in the vasculature of aged animals as well as in aging-associated vascular dysfunction are necessary and expected.

\section{DRUGS THAT AFFECT NO GENERATION/TURNOVER: A TREATMENT FOR AGING-ASSOCIATED VASCULAR DYSFUNCTION IN HUMANS?}

Due to its protective role on vascular homeostasis, adequate NO synthesis and signaling represents an important goal in the treatment of vascular dysfunction. Therefore it is important to understand the cellular and molecular mechanisms that control the function and expression of NOS isoforms as well as the implications this may have for aging-associated vascular dysfunction. Unfortunately, as specific NOS isoforms pharmacological inhibitors are still limited for experimental interventions or local administration in humans, the effects of selective NOS activity inhibition and/or stimulation remains unknown. 


\section{RESTORING NO LEVELS}

Due to their ability to restore reduced NO bioavailability, NOdonors represent a therapeutic strategy to treat aging-associated CVD. Although acute administration of the NO-donor sodium nitroprusside improved cardiovascular performance at rest and during exercise in healthy older volunteers (Chantler et al., 2011), inorganic and organic nitrates (e.g., nitroglycerin) are a class of compounds with limited long-term therapeutic use due to the induction of tolerance. Experimentally, NO-releasing nonsteroidal anti-inflammatory drugs (NO-NSAID), which are prodrugs that contain a NO-donor moiety chemically attached to a parent NSAID, have shown promising anti-inflammatory activity and NO-releasing properties (Fiorucci et al., 2001). NO-releasingaspirin, but not aspirin, reduced vascular smooth muscle cell proliferation in response to vascular injury in old rats (Napoli et al., 2002), an effect that may be clinically relevant in the treatment of aging-associated vascular remodeling.

An emerging alternative to directly increase NO levels is represented by nitrite anions. Different schedules of inorganic nitrite supplementation as well as nitrite-rich diets have been shown to induce vascular relaxation and to reduce blood pressure (Cosby et al., 2003; Larsen et al., 2006; Webb et al., 2008; Kapil et al., 2010). A traditional Japanese diet, for a 10-day-period, increased plasma levels of nitrite and lowered blood pressure in healthy volunteers (Sobko et al., 2010). These results suggest that the higher longevity in the Japanese population compared to the occidental population may be associated with high levels of nitrites on their diet. There is a general agreement that inorganic and dietary nitrites can be therapeutically used to treat CVD and possibly, cardiovascular aging. However, uncertainties about the safety of nitrites limit clinical interventions. To our knowledge, there is just one report showing an association between high nitrite consumption and increased regional brain perfusion in elderly subjects (Presley et al., 2011). Since cerebral hypoperfusion precedes and contributes to the onset of clinical dementia, this finding has clinical relevance.

\section{STATINS}

Inhibitors of cholesterol synthesis, the statins, represent a therapeutic alternative to treat vascular aging. In addition to improvement in lipid profile, these drugs increase NO bioavailability by many mechanisms that include: increased eNOS expression due to increased eNOS mRNA stability and post-transcriptional modifications (Laufs and Liao, 1998; Laufs et al., 1998), eNOS recoupling (Wenzel et al., 2008; Sabri et al., 2011), and reduced NO breakdown by ROS (Figure 2) (Wagner et al., 2000; Wenzel et al., 2008). Additionally, atorvastatin up-regulates nNOS expression in endothelial cells in vitro, and about a quarter of the total $\mathrm{NO}$ production in aortic rings were attributed to atorvastatin-induced nNOS expression (Nakata et al., 2007). These pleiotropic effects of statins help to justify the huge number of clinical trials addressing the benefits of statin treatment in CVD (revised by Baigent et al., 2005).

Experimentally, statins reverse impaired endotheliumdependent vasodilation in old rats and increase vascular levels of eNOS (de Sotomayor et al., 2005). Conversely, impaired endothelium-dependent vasodilatation was not modified by atorvastatin treatment in elderly subjects without associated morbidities (Weverling-Rijnsburger et al., 2004). Although this finding seems to be disappointing, observational studies reported that statin treatment lowered the ratio of fatal outcomes in elderly with CVD (Foody et al., 2006; Gransbo et al., 2010). In the double-blind, randomized, placebo-controlled multicenter study PROspective Study of Pravastatin in the Elderly at Risk (PROSPER), pravastatin was found to reduce death caused by coronary heart disease and the risk for non-fatal myocardial infarction in the treated elderly group (Shepherd et al., 2002), reinforcing the suggestion that statins may prevent cardiovascular aging.

Transgenic mouse with endothelial-targeted overexpression of guanosine triphosphate cyclohydrolase-1 (GTPCH-1), the ratelimiting enzyme for de novo $\mathrm{BH}_{4}$ synthesis, does not exhibit diabetes-associated vascular abnormalities (Alp et al., 2003). Whereas streptozotocin (STZ) increases vascular oxidative stress and impairs NO-mediated endothelium-dependent vasodilatation in control mice, STZ-treated transgenic GTPCH-1 mice exhibit less superoxide production and normal NO-mediated vasodilatation (Alp et al., 2003). Similarly, treatment of hypertensive rats with simvastatin restored GTPCH-1 activity and the $\mathrm{BH}_{4} / \mathrm{eNOS} / \mathrm{NO}$ pathway reversing the hypertension-associated endothelial dysfunction (Zhang et al., 2012). In vitro, statins rapidly increase $\mathrm{BH}_{4}$ bioavailability and up-regulate GTPCH-1, leading to eNOS recoupling and NO generation in endothelial cells (Hattori et al., 2003; Aoki et al., 2012; Zhang et al., 2012). Of importance, patients with coronary artery disease treated with atorvastatin showed very early improvement of flow-mediated dilation in the brachial artery and restored $\mathrm{BH}_{4}$ levels in mammary arteries compared with the placebo group (Antoniades et al., 2011). Moreover, the incubation of human mammary arteries with atorvastatin augmented GTPCH-1 expression (Antoniades et al., 2011). Collectively, experimental findings indicate that statins produce beneficial vascular effects via actions in the $\mathrm{GTPCH} / \mathrm{BH}_{4} / \mathrm{NO}$ pathway and may be used for the treatment of vascular aging.

\section{HORMONE THERAPIES: DEHYDROEPIANDROSTERONE (DHEA) AND ESTROGEN}

Therapy with hormones, mainly dehydroepiandrosterone (DHEA) and estrogen, has been considered a "treatment for aging" (Figure 2) (Lamberts et al., 1997). DHEA replacement therapy improved endothelium-dependent dilation in normotensive hypercholesterolemic men and post-menopause women (Kawano et al., 2003; Williams et al., 2004). One potential explanation for the above observations is based on experimental data on DHEAtreated old rats. These animals showed increased aortic eNOS expression and restored NO production, although the repercussion on vascular function was not investigated (Wu et al., 2007). Disappointingly, a set of clinical observations reported null effects with DHEA supplementation in men with CVD (Traish et al., 2011).

Despite of the controversy about the benefits of estrogen replacement therapy in post-menopausal women, cardiovascular benefits of estrogen have been attributed to its modulatory effects on NO generation by NOS isoforms (Xing et al., 2009). Estrogen deficiency, induced by ovariectomy, further increased aging-associated vasoconstriction and impaired NO signaling (Stice et al., 2009; Novella et al., 2010). Estrogen replacement also improved flow-induced vasodilation in coronary arterioles 


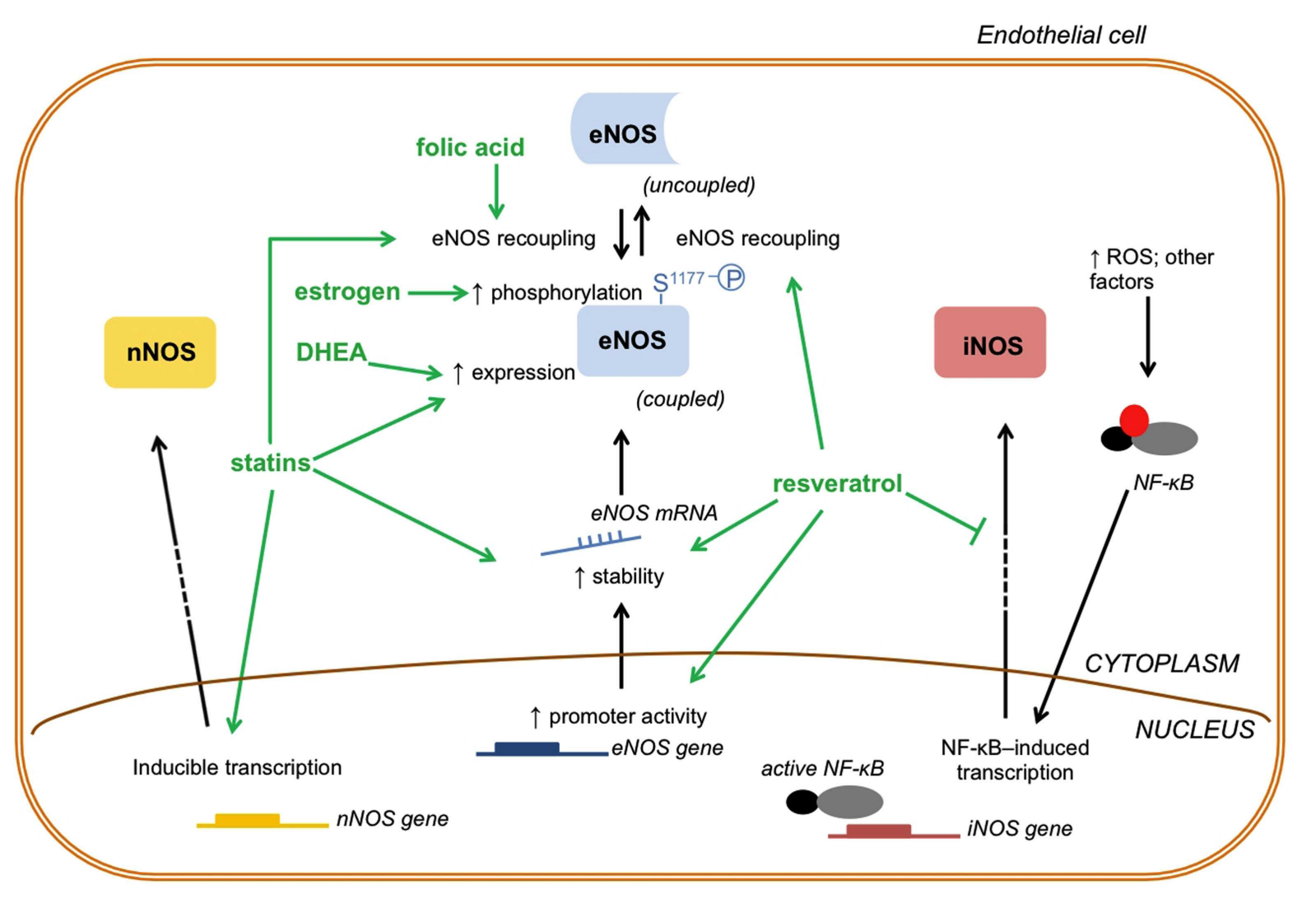

FIGURE 2 | Drugs that affect NO generation/turnover by modulating NOS enzymes. The drugs that modulate NOS enzymes and, consequently NO production, act by changing three important aspects of NOS enzymes function: activity, expression and transcription: (1) activity; estrogen induces eNOS phosphorylation at $\left(S^{1177}\right)$ to increase enzyme activity; statins and folic acid may cause eNOS recoupling to increase eNOS activity and NO production; (2) expression; statins and DHEA increase eNOS expression and, consequently, NO generation; (3) transcription; statins and resveratrol act at the transcriptional level of eNOS increasing its mRNA stability. In addition, resveratrol activates the promoter gene of eNOS increasing its transcription. Whereas eNOS enzyme function can be altered in three different ways, nNOS and iNOS function can be modulated at the transcriptional level by some of these drugs. Statins may directly induce nNOS transcription and increase nNOS protein levels. On the other hand, resveratrol indirectly decreases iNOS transcription by inhibiting NF-кB. DHEA, dehydroepiandrosterone; ROS, reactive oxygen species; NF-кB, nuclear factor kappa $B$; mRNA, messenger RNA. of aged and ovariectomized rats and restored eNOS phosphorylation (Ser ${ }^{1176}$ ), suggesting a positive regulation of estrogen on eNOS activity in old females (LeBlanc et al., 2009). In addition, vascular dysfunction in aged female rats is associated with both decreased levels of estrogen and an altered pattern of estrogen receptor-mediated $\mathrm{NO}$-induced vascular relaxation (Novensa et al., 2011). This provides a new insight for the refractoriness of age-related vascular dysfunction to estrogen replacement therapy.

Beneficial and harmful effects of estrogen on the vasculature are also associated to iNOS protein expression. Ovariectomized rats exhibited greater vascular iNOS expression than intact animals and estrogen replacement reduced iNOS expression in ovariectomized rats (Tamura et al., 2000). Therefore, it is possible that vascular dysfunction that accompanies estrogen withdrawal is related to increased iNOS levels. However, estrogen replacement reversed the vascular remodeling in injured arteries from ovariectomized mice that do not express iNOS, suggesting that estrogen-associated vascular protection is not only related to suppression of iNOS expression/activity (Tolbert et al., 2001). Conversely, estrogen has been shown to attenuate vasoconstriction by an estrogen receptor beta-mediated increase in iNOS expression (Zhu et al., 2002). The physiological significance of iNOS activation by estrogen on vascular tonus remains uncertain, since the absence of either alpha or beta estrogen receptors, which increases vascular iNOS, does not affect vascular sensitivity to vasoconstrictors (Liang et al., 2003). The protective effect associated with estrogen-induced iNOS expression may be related to a reduction in thrombotic events, since the gender-associated protection against experimentally induced thrombosis is lost in female mice that do not express iNOS (Upmacis et al., 2011). These data suggest that basal levels of estrogen can actively produce NO via iNOS and inhibit thrombus formation in females. Although yet untested, it is unlikely that estrogen replacement therapy elicits this effect, since a metaanalysis of observational studies reported a statistically increase in the risk for thromboembolic events among estrogen users (Nelson et al., 2002).

With regard to nNOS, it was demonstrated that endotheliumdependent relaxation of resistance arteries by estrogen is nNOS- 
dependent in female, whereas it is eNOS-dependent in males (Lekontseva et al., 2011). Although the results of estrogen-induced relaxation via nNOS are extremely encouraging, the physiological significance of these findings has yet to be determined. Additionally, the effects of aging and estrogen replacement therapy in this phenomenon are poorly understood and more studies are needed. Finally, it must be considered that hormone replacement therapy in women is usually prescribed as a combination of estrogen and progestin (a synthetic analog of progesterone). The estrogen/progestin association may cause differential vascular effects than those produced by estrogen alone (Qiao et al., 2008).

\section{RESVERATROL}

Accumulating evidence support that resveratrol, a natural occurring polyphenol derived from plants such as grapes, exerts antiaging effects. There are several genes and proteins known to influence longevity, such as the mammalian target of rapamycin (mTOR) - see a recent review and also a comment on topic (Cau and Tostes, 2012; Ming et al., 2012) - and sirtuin families pathways, which have been involved in the anti-aging properties of resveratrol (Pallàs et al., 2010). Whereas resveratrol extends lifespan in yeast and nematode, the polyphenol has been shown to increase survival rate in mice on a high-calorie diet. Resveratrol increased insulin sensitivity and improved motor function in these animals (Baur et al., 2006). In addition, resveratrol has been shown to inhibit gene expression profiles associated with cardiac and skeletal muscle aging, and prevent age-related cardiac dysfunction (Barger et al., 2008). Of special interest, resveratrol prevents vascular cell senescence by mechanisms that involve increased NO production by eNOS via multifaceted signaling pathways (Schmitt et al., 2010). Resveratrol not only restores eNOS activity, but it induces eNOS transcription via direct activation of the eNOS gene promoter and by increasing the stability of eNOS mRNA (Figure 2) (Wallerath et al., 2002).

Due to these various effects, resveratrol treatment has been experimentally tested and considered for a wide variety of CVD, including hypertension, atherosclerosis, diabetes and metabolic syndrome (Li et al., 2012). In general, there is a growing body of evidence to support the benefits of red wine consumption (a rich dietary source of resveratrol) to reduce CVD risk in obesity (Timmers et al., 2011; Wong et al., 2011), diabetes (Kar et al., 2009; Brasnyo et al., 2011), and coronary artery disease (Whelan et al., 2004; Lekakis et al., 2005). A pilot study in older adults treated with resveratrol reported a trend toward improved endothelial function (Crandall et al., 2012); however, larger studies in elderly are still awaited.

Although resveratrol-induced dilation of isolated small mesenteric arteries is similar in young and aged rats, treatment with resveratrol reduces aging-associated vascular $\bullet \mathrm{O}_{2}^{-}$production and inflammation (Labinskyy et al., 2006). Resveratrol also reversed eNOS uncoupling, reduced NO synthesis, and increased $\bullet \mathrm{O}_{2}^{-}$ production in senescent endothelial cells in vitro as well as in aortas of aged rats (Rajapakse et al., 2011). Similarly, vascular and cardiac eNOS recoupling was reported in resveratrol-treated spontaneously hypertensive rats (Bhatt et al., 2011) and in a mouse model of atherogenesis (Xia et al., 2010), respectively.
In addition, endothelium-dependent vasodilation was restored in resveratrol-treated old rats (Rajapakse et al., 2011).

The anti-inflammatory properties of resveratrol are related to its regulatory effects on the activity of transcription factors, particularly NF-kappaB (NF-кB; Labinskyy et al., 2006). NF$\kappa \mathrm{B}$-induced expression of pro-inflammatory genes is involved in aging-associated vascular dysfunction (Donato et al., 2009). Therefore, inhibition of NF- $\kappa \mathrm{B}$ by resveratrol may reverse the increased iNOS expression in aged arterioles, and consequently improve vascular function (Labinskyy et al., 2006). However, this effect has not been experimentally demonstrated.

\section{AGENTS TO REVERSE ENOS UNCOUPLING}

Reversing eNOS uncoupling represents a therapeutic option to treat CVD (Forstermann and Li, 2011; Zhang et al., 2011). While most interventions are experimentally restricted, eNOS cofactor $\mathrm{BH}_{4}$ potentially leads to eNOS recoupling in the human vasculature (Forstermann and Li, 2011; Zhang et al., 2011). Infusion of $\mathrm{BH}_{4}$ has been shown to recover eNOS bioactivity in hypercholesterolemic patients, hypertensive subjects, and smokers (revised by Forstermann and Li, 2011; Zhang et al., 2011). Importantly, improved endothelium-dependent vasodilation associated to $\mathrm{BH}_{4}$ infusion was significantly more pronounced in elderly than in young subjects (Higashi et al., 2006). A recent study showed that an oral dose of $\mathrm{BH}_{4}$ increased carotid artery compliance and brachial artery flow-mediated dilation in post-menopausal women (Moreau et al., 2012). The authors also addressed whether $\mathrm{BH}_{4}$ and estrogen co-administration would bring additional improvement in vascular function, but no further effects were observed (Moreau et al., 2012). It is important to highlight that these studies were performed with acute doses of $\mathrm{BH}_{4}$ and, although promising, $\mathrm{BH}_{4}$ supplementation potentially leads to excessive and tissue unspecific NO production and toxicity (Moens and Kass, 2006).

Interactions of 5-methyltetrahydrofolate (5-MTHF), the active metabolite of folic acid, with eNOS protein have been described (Moens et al., 2008). Likewise, 5-MTHF restores the bioavailability of $\mathrm{BH}_{4}$ by increasing the binding affinity of $\mathrm{BH}_{4}$ to eNOS, by chemically stabilizing $\mathrm{BH}_{4}$, and by enhancing the regeneration of $\mathrm{BH}_{4}$ from its inactive form $\mathrm{BH}_{2}$ (Figure 2) (Moens et al., 2008). 5-MTHF reversed eNOS uncoupling and restored NO-mediated vasodilation and reduced vascular superoxide, both ex vivo and in vivo (Antoniades et al., 2006). Interestingly, this study was performed in early elderly subjects $(67.2 \pm 0.97$ years old $)$ with coronary artery disease (Antoniades et al., 2006). Similarly, the treatment of hypertensive mice with folic acid prevented aneurism formation and promotes eNOS recoupling (Gao et al., 2012).

At least two limitations on folic acid enrichment must be pointed out. First, high levels of folic acid can mask the diagnosis of pernicious anemia (deficiency of vitamin $\mathrm{B}_{12}$ ) and allow the neuropathy to progress undiagnosed. This could be particularly limiting for the elderly, where substantial ratio of plasmatic levels of non-metabolized folic acid was found after supplementation (Obeid et al., 2011). However, this can be easily corrected by co-supplementation with vitamin $\mathrm{B}_{12}$ which further ameliorates coronary flow parameters (Kurt et al., 2010). Second, the significance of folic acid supplementation to prevent major 
cardiovascular events was recently questioned in a systematic revision of clinical studies (Zhou et al., 2011), and whether this mechanism on eNOS recoupling occurs in old people treated with folic acid and represents a rational therapeutic target remains unclear.

\section{CONCLUSION AND PERSPECTIVES}

The mechanisms by which NOS enzymes promote vascular dysfunction in aging are specific for each enzyme isoform. eNOS expression and activity are decreased in aging, resulting in reduced NO synthesis. Advancing aging is also accompanied by eNOS uncoupling, which contributes to vascular oxidative stress. iNOS expression is augmented in elderly, leading to reduced endothelium-dependent vasodilation and increased damage via formation of the reactive specie peroxynitrite. Possibly, an impairment of perivascular nNOS-released NO increases vasoconstrictor tone. These data suggest a differential regulation of the NOS family isoforms in the process of vascular aging, which is associated with

\section{REFERENCES}

Alp, N. J., Mussa, S., Khoo, J., Cai, S., Guzik, T., Jefferson, A., Goh, N., Rockett, K. A., and Channon, K. M. (2003). Tetrahydrobiopterindependent preservation of nitric oxide-mediated endothelial function in diabetes by targeted transgenic GTP-cyclohydrolase I overexpression. J. Clin. Invest. 112, 725-735.

Antoniades, C., Bakogiannis, C., Leeson, P., Guzik, T. J., Zhang, M. H., Tousoulis, D., Antonopoulos, A. S., Demosthenous, M., Marinou, K., Hale, A., Paschalis, A., Psarros, C., Triantafyllou, C., Bendall, J., Casadei, B., Stefanadis, C., and Channon, K. M. (2011). Rapid, direct effects of statin treatment on arterial redox state and nitric oxide bioavailability in human atherosclerosis via tetrahydrobiopterinmediated endothelial nitric oxide synthase coupling. Circulation 124, 335-345.

Antoniades, C., Shirodaria, C., Warrick, N., Cai, S., de Bono, J., Lee, J., Leeson, P., Neubauer, S., Ratnatunga, C., Pillai, R., Refsum, H., and Channon, K. M. (2006). 5-Methyltetrahydrofolate rapidly improves endothelial function and decreases superoxide production in human vessels: effects on vascular tetrahydrobiopterin availability and endothelial nitric oxide synthase coupling. Circulation 114, 1193-1201.

Aoki, C., Nakano, A., Tanaka, S., Yanagi, K., Ohta, S., Jojima, T., Kasai, K., Takekawa, H., Hirata, K., and Hattori, Y. (2012). Fluvastatin upregulates endothelial nitric oxide synthase activity via enhancement of its phosphorylation and expression and via an increase in tetrahydrobiopterin in vascular endothelial cells. Int. J. Cardiol. 156, 55-61.

Baigent, C., Keech, A., Kearney, P. M., Blackwell, L., Buck, G., Pollicino, C., Kirby, A., Sourjina, T., Peto, R., Collins, R., and Simes, R. (2005). Efficacy and safety of cholesterol-lowering treatment: prospective meta-analysis of data from 90,056 participants in 14 randomised trials of statins. Lancet 366 , 1267-1278.

Barger, J. L., Kayo, T., Vann, J. M., Arias, E. B., Wang, J., Hacker, T. A., Wang, Y., Raederstorff, D., Morrow, J. D., Leeuwenburgh, C., Allison, D. B., Saupe, K. W., Cartee, G. D., Weindruch, R., and Prolla, T. A. (2008). A low dose of dietary resveratrol partially mimics caloric restriction and retards aging parameters in mice. PLoS ONE 3, e2264. doi:10.1371/journal.pone.0002264

Baur, J. A., Pearson, K. J., Price, N. L., Jamieson, H. A., Lerin, C., Kalra, A., Prabhu, V. V., Allard, J. S., LopezLluch, G., Lewis, K., Pistell, P. J., Poosala, S., Becker, K. G., Boss, O., Gwinn, D., Wang, M., Ramaswamy, S., Fishbein, K. W., Spencer, R. G., Lakatta, E. G., Le Couteur, D., Shaw, D. K., de Cabo, R., and Sinclair, D. A. (2006). Resveratrol improves health and survival of mice on a highcalorie diet. Nature 444, 337-342.

Bhatt, S. R., Lokhandwala, M. F., and Banday, A. A. (2011). Resveratrol prevents endothelial nitric oxide synthase uncoupling and attenuates development of hypertension in spontaneously hypertensive rats. Eur. J. Pharmacol. 667, 258-264.

Blackwell, K. A., Sorenson, J. P., Richardson, D. M., Smith, L. A., Suda, O., Nath, K., and Katusic, Z. S. (2004). Mechanisms of aging-induced impairment of R. J., Navas, P., Puigserver, P., Ingram,

reduced $\mathrm{NO}$ and increased $\bullet \mathrm{O}_{2}^{-}$production, and to the vascular dysfunction that lead to aging-related CVD.

Due to additional effects on the NOS pathway, e.g., restoration of eNOS activity and decreased RNS formation, drugs clinically used to treat hypercholesterolemia and post-menopause symptoms, such as statin and estrogen, respectively, have also been considered for the treatment of cardiovascular aging. Dietary alternatives to treat vascular aging include nitrite-rich meals and folic acid supplementation, although many questions on the safety and effectiveness of long-term regimes were not elucidated so far. Resveratrol is accepted as a key pharmacological agent for prevention and treatment of aging, which interferes at multiple molecular levels in aging-related vascular dysfunction. Although it is clear that all the pharmacological agents reviewed herein produce important and beneficial cardiovascular effects, it is necessary to clinically determine whether these treatments extend lifespan.

endothelium-dependent relaxation: role of tetrahydrobiopterin. Am. J. Physiol. Heart Circ. Physiol. 287, H2448-H2453.

Bolli, R. (2001). Cardioprotective function of inducible nitric oxide synthase and role of nitric oxide in myocardial ischemia and preconditioning: an overview of a decade of research. J. Mol. Cell. Cardiol. 33, 1897-1918.

Brasnyo, P., Molnar, G. A., Mohas, M., Marko, L., Laczy, B., Cseh, J., Mikolas, E., Szijarto, I. A., Merei, A., Halmai, R., Meszaros, L. G., Sumegi, B., and Wittmann, I. (2011). Resveratrol improves insulin sensitivity, reduces oxidative stress and activates the Akt pathway in type 2 diabetic patients. Br. J. Nutr. 106, 383-389.

Briones, A. M., Montoya, N., Giraldo, J., and Vila, E. (2005). Ageing affects nitric oxide synthase, cyclooxygenase and oxidative stress enzymes expression differently in mesenteric resistance arteries. Auton. Autacoid Pharmacol. 25, 155-162.

Cau, S. B., and Tostes, R. C. (2012). mTOR Inhibition: a promise for a young heart. Front. Physiol. 3:31. doi:10.3389/fphys.2012.00031

Cernadas, M. R., Sanchez de Miguel, L., Garcia-Duran, M., GonzalezFernandez, F., Millas, I., Monton, M., Rodrigo, J., Rico, L., Fernandez, P., de Frutos, T., Rodriguez-Feo, J. A., Guerra, J., Caramelo, C., Casado, S., and Farre, L. (1998). Expression of constitutive and inducible nitric oxide synthases in the vascular wall of young and aging rats. Circ. Res. 83, 279-286.

Challah, M., Nadaud, S., Philippe, M., Battle, T., Soubrier, F., Corman, B., and Michel, J. B. (1997). Circulating and cellular markers of endothelial dysfunction with aging in rats. Am. J. Physiol. 273(Pt 2), H1941-H1948.
Chantler, P. D., Nussbacher, A., Gerstenblith, G., Schulman, S. P., Becker, L. C., Ferrucci, L., Fleg, J. L., Lakatta, E. G., and Najjar, S. S. (2011). Abnormalities in arterial-ventricular coupling in older healthy persons are attenuated by sodium nitroprusside. Am. J. Physiol. Heart Circ. Physiol. 300, H1914-H1922.

Chou, T. C., Yen, M. H., Li, C. Y., and Ding, Y. A. (1998). Alterations of nitric oxide synthase expression with aging and Hypertension in rats. Hypertension 31, 643-648.

Cosby, K., Partovi, K. S., Crawford, J. H., Patel, R. P., Reiter, C. D., Martyr, S., Yang, B. K., Waclawiw, M. A., Zalos, G., Xu, X., Huang, K. T., Shields, H., Kim-Shapiro, D. B., Schechter, A. N., Cannon, R. O. III., and Gladwin, M. T. (2003). Nitrite reduction to nitric oxide by deoxyhemoglobin vasodilates the human circulation. Nat. Med. 9, 1498-1505.

Crandall, J. P., Oram, V., Trandafirescu, G., Reid, M., Kishore, P., Hawkins, M., Cohen, H. W., and Barzilai, N. (2012). Pilot study of resveratrol in older adults with impaired glucose tolerance. J. Gerontol. A Biol. Sci. Med. Sci. 67A, 1-6.

Csiszar, A., Ungvari, Z., Edwards, J. G., Kaminski, P., Wolin, M. S., Koller, A., and Kaley, G. (2002). Aging-induced phenotypic changes and oxidative stress impair coronary arteriolar function. Circ. Res. 90, 1159-1166.

de Sotomayor, M. A., Perez-Guerrero, C., Herrrera, M. D., Jimenez, L., Marin, R., Marhuenda, E., and Andriantsitohaina, R. (2005). Improvement of age-related endothelial dysfunction by simvastatin: effect on $\mathrm{NO}$ and COX pathways. Br. J. Pharmacol. 146, 1130-1138. 
Dejam, A., Hunter, C. J., Schechter, A. N., and Gladwin, M. T. (2004). Emerging role of nitrite in human biology. Blood Cells Mol. Dis. 32, 423-429.

Delp, M. D., Behnke, B. J., Spier, S. A., Wu, G., and Muller-Delp, J. M. (2008). Ageing diminishes endothelium-dependent vasodilatation and tetrahydrobiopterin content in rat skeletal muscle arterioles. J. Physiol. (Lond.) 586, 1161-1168.

Denniss, S. G., Levy, A. S., and Rush, J. W. (2011). Effects of glutathionedepleting drug buthionine sulfoximine and aging on activity of endothelium-derived relaxing and contracting factors in carotid artery of sprague-dawley rats. J. Cardiovasc. Pharmacol. 58, 272-283.

Dere, E., De Souza Silva, M. A., Topic, B., Fiorillo, C., Li, J. S., Sadile, A. G., Frisch, C., and Huston, J. P. (2002). Aged endothelial nitric oxide synthase knockout mice exhibit higher mortality concomitant with impaired open-field habituation and alterations in forebrain neurotransmitter levels. Genes Brain Behav. 1, 204-213.

Donato, A. J., Pierce, G. L., Lesniewski, L. A., and Seals, D. R. (2009). Role of NFkappaB in age-related vascular endothelial dysfunction in humans. Aging (Albany NY) 1, 678-680.

Dudzinski, D. M., and Michel, T. (2007). Life history of eNOS: partners and pathways. Cardiovasc. Res. 75, 247-260.

Ferrer, M., and Balfagon, G. (2001). Aging alters neuronal nitric oxide release from rat mesenteric arteries: role of presynaptic beta-adrenoceptors. Clin. Sci. 101, 321-328.

Ferrer, M., Sanchez, M., Minoves, N., Salaices, M., and Balfagon, G. (2003). Aging increases neuronal nitric oxide release and superoxide anion generation in mesenteric arteries from spontaneously hypertensive rats. J. Vasc. Res. 40, 509-519.

Fiorucci, S., Antonelli, E., Burgaud, J. L., and Morelli, A. (2001). Nitric oxide-releasing NSAIDs: a review of their current status. Drug Saf. 24, 801-811.

Fleenor, B. S., Seals, D. R., Zigler, M. L., and Sindler, A. L. (2011). Superoxide-lowering therapy with TEMPOL reverses arterial dysfunction with aging in mice. Aging Cell 11, 269-276.

Foody, J. M., Rathore, S. S., Galusha, D., Masoudi, F. A., Havranek, E. P., Radford, M. J., and Krumholz, H. M. (2006). HydroxymethylglutarylCoA reductase inhibitors in older persons with acute myocardial infarction: evidence for an age-statin interaction. J. Am. Geriatr. Soc. 54, 421-430.

Forstermann, U., and Li, H. (2011). Therapeutic effect of enhancing endothelial nitric oxide synthase (eNOS) expression and preventing eNOS uncoupling. Br. J. Pharmacol. 164, 213-223.

Fulop, N., Feng, W., Xing, D., He, K., Not, L. G., Brocks, C. A., Marchase, R. B., Miller, A. P., and Chatham, J. C. (2008). Aging leads to increased levels of protein O-linked $\mathrm{N}$-acetylglucosamine in heart, aorta, brain and skeletal muscle in Brown-Norway rats. Biogerontology 9, 139-151.

Gao, L., Siu, K. L., Chalupsky, K., Nguyen, A., Chen, P., Weintraub, N. L., Galis, Z., and Cai, H. (2012). Role of uncoupled endothelial nitric oxide synthase in abdominal aortic aneurysm formation: treatment with folic acid. Hypertension 59, 158-166.

Gates, P. E., Boucher, M. L., Silver, A. E., Monahan, K. D., and Seals, D. R. (2007). Impaired flowmediated dilation with age is not explained by L-arginine bioavailability or endothelial asymmetric dimethylarginine protein expression. J. Appl. Physiol. 102, 63-71.

Gerhard, M., Roddy, M. A., Creager, S. J., and Creager, M. A. (1996). Aging progressively impairs endothelium-dependent vasodilation in forearm resistance vessels of humans. Hypertension 27, 849-853.

Glenn, C. L., Wang, W. Y., and Morris, B. J. (1999). Different frequencies of inducible nitric oxide synthase genotypes in older hypertensives. Hypertension 33, 927-932.

Goettsch, W., Lattmann, T., Amann, K., Szibor, M., Morawietz, H., Munter, K., Muller, S. P., Shaw, S., and Barton, M. (2001). Increased expression of endothelin-1 and inducible nitric oxide synthase isoform II in aging arteries in vivo: implications for atherosclerosis. Biochem. Biophys. Res. Commun. 280, 908-913.

Gransbo, K., Melander, O., Wallentin, L., Lindback, J., Stenestrand, U., Carlsson, J., and Nilsson, J. (2010). Cardiovascular and cancer mortality in very elderly post-myocardial infarction patients receiving statin treatment. J. Am. Coll. Cardiol. 55, 1362-1369.

Hamilton, C. A., Brosnan, M. J., McIntyre, M., Graham, D., and Dominiczak, A. F. (2001). Superoxide excess in hypertension and aging: a common cause of endothelial dysfunction. Hypertension $37 \mathrm{Pt}$ 2), 529-534.

Hattori, Y., Nakanishi, N., Akimoto, K. Yoshida, M., and Kasai, K. (2003). HMG-CoA reductase inhibitor increases GTP cyclohydrolase I mRNA and tetrahydrobiopterin in vascular endothelial cells. Arterioscler. Thromb. Vasc. Biol. 23 176-182.

Hecker, M., Cattaruzza, M., and Wagner, A. H. (1999). Regulation of inducible nitric oxide synthase gene expression in vascular smooth muscle cells. Gen. Pharmacol. 32, 9-16.

Herrera, M. D., Mingorance, C., Rodriguez-Rodriguez, R., and Alvarez de Sotomayor, M. (2010). Endothelial dysfunction and aging: an update. Ageing Res. Rev. 9, 142-152.

Higashi, Y., Sasaki, S., Nakagawa, K., Kimura, M., Noma, K., Hara, K., Jitsuiki, D., Goto, C., Oshima, T., Chayama, K., and Yoshizumi, M. (2006). Tetrahydrobiopterin improves aging-related impairment of endothelium-dependent vasodilation through increase in nitric oxide production. Atherosclerosis 186, 390-395.

Kapil, V., Milsom, A. B., Okorie, M. Maleki-Toyserkani, S., Akram, F., Rehman, F., Arghandawi, S., Pearl, V., Benjamin, N., Loukogeorgakis, S., MacAllister, R., Hobbs, A. J., Webb, A. J., and Ahluwalia, A. (2010). Inorganic nitrate supplementation lowers blood pressure in humans: role for nitrite-derived NO. Hypertension 56, 274-281.

Kar, P., Laight, D., Rooprai, H. K., Shaw, K. M., and Cummings, M. (2009). Effects of grape seed extract in Type 2 diabetic subjects at high cardiovascular risk: a double blind randomized placebo controlled trial examining metabolic markers, vascular tone, inflammation, oxidative stress and insulin sensitivity. Diabet. Med. 26, 526-531.

Kawano, H., Yasue, H., Kitagawa, A., Hirai, N., Yoshida, T., Soejima, H., Miyamoto, S., Nakano, M., and Ogawa, H. (2003). Dehydroepiandrosterone supplementation improves endothelial function and insulin sensitivity in men. J. Clin. Endocrinol. Metab. 88, 3190-3195.

Kim, J. H., Bugaj, L. J., Oh, Y. J., Bivalacqua, T. J., Ryoo, S., Soucy, K. G., Santhanam, L., Webb, A., Camara, A., Sikka, G., Nyhan, D., Shoukas, A. A., Ilies, M., Christianson, D. W., Champion, H. C., and Berkowitz, D. E. (2009). Arginase inhibition restores
NOS coupling and reverses endothelial dysfunction and vascular stiffness in old rats. J. Appl. Physiol. 107, 1249-1257.

Kurt, R., Yilmaz, Y., Ermis, F., Kalayoglu Besisik, S., Polat, N., Elitok, A., Oflaz, H., and Karan, M. A. (2010). Folic Acid and vitamin B12 supplementation improves coronary flow reserve in elderly subjects with vitamin B12 deficiency. Arch. Med. Res. 41, 369-372.

Labinskyy, N., Csiszar, A., Veress, G. Stef, G., Pacher, P., Oroszi, G., Wu, J., and Ungvari, Z. (2006). Vascular dysfunction in aging: potential effects of resveratrol, an antiinflammatory phytoestrogen. Curr. Med. Chem. 13, 989-996.

Lakatta, E. G., and Levy, D. (2003). Arterial and cardiac aging: major shareholders in cardiovascular disease enterprises: Part I: aging arteries: a "set up" for vascular disease. Circulation 107, 139-146.

Lamberts, S. W., van den Beld, A. W., and van der Lely, A. J. (1997). The endocrinology of aging. Science 278, 419-424.

Larsen, F. J., Ekblom, B., Sahlin, K., Lundberg, J. O., and Weitzberg, E. (2006). Effects of dietary nitrate on blood pressure in healthy volunteers. N. Engl. J. Med. 355, 2792-2793.

Laufs, U., La Fata, V., Plutzky, J., and Liao, J. K. (1998). Upregulation of endothelial nitric oxide synthase by HMG CoA reductase inhibitors. Circulation 97, 1129-1135.

Laufs, U., and Liao, J. K. (1998). Post-transcriptional regulation of endothelial nitric oxide synthase mRNA stability by Rho GTPase. J. Biol. Chem. 273, 24266-24271.

LeBlanc, A. J., Reyes, R., Kang, L. S., Dailey, R. A., Stallone, J. N., Moningka, N. C., and Muller-Delp, J. M. (2009). Estrogen replacement restores flow-induced vasodilation in coronary arterioles of aged and ovariectomized rats. Am. J. Physiol. Regul. Integr. Comp. Physiol. 297, R1713-R1723.

Lekakis, J., Rallidis, L. S., Andreadou, I., Vamvakou, G., Kazantzoglou, G., Magiatis, P., Skaltsounis, A. L., and Kremastinos, D. T. (2005). Polyphenolic compounds from red grapes acutely improve endothelial function in patients with coronary heart disease. Eur. J. Cardiovasc. Prev. Rehabil. 12, 596-600.

Lekontseva, O., Chakrabarti, S., Jiang, Y., Cheung, C. C., and Davidge, S. T. (2011). Role of neuronal nitricoxide synthase in estrogen-induced relaxation in rat resistance arteries. $J$. Pharmacol. Exp. Ther. 339, 367-375. 
Li, H., Xia, N., and Forstermann, U. (2012). Cardiovascular effects and molecular targets of resveratrol. Nitric Oxide 26, 102-110.

Liang, M., Ekblad, E., Lydrup, M. L., and Nilsson, B. O. (2003). Combined lack of estrogen receptors alpha and beta affects vascular iNOS protein expression. Cell Tissue Res. 313, 63-70.

Lima, V. V., Rigsby, C. S., Hardy, D. M., Webb, R. C., and Tostes, R. C. (2009). O-GlcNAcylation: a novel post-translational mechanism to alter vascular cellular signaling in health and disease: focus on hypertension. J. Am. Soc. Hypertens. 3, 374-387.

Lund, D. D., Chu, Y., Miller, J. D., and Heistad, D. D. (2009). Protective effect of extracellular superoxide dismutase on endothelial function during aging. Am. J. Physiol. Heart Circ. Physiol. 296, H1920-H1925.

Matz, R. L., de Sotomayor, M. A., Schott, C., Stoclet, J. C., and Andriantsitohaina, R. (2000). Vascular bed heterogeneity in age-related endothelial dysfunction with respect to NO and eicosanoids. Br. J. Pharmacol. 131, 303-311.

Melikian, N., Seddon, M. D., Casadei, B., Chowienczyk, P. J., and Shah, A. M. (2009). Neuronal nitric oxide synthase and human vascular regulation. Trends Cardiovasc. Med. 19, 256-262.

Ming, X. F., Montani, J. P., and Yang, Z. (2012). Perspectives of targeting mTORC1-S6K1 in cardiovascular aging. Front. Physiol. 3:5. doi:10.3389/fphys.2012.00005

Moens, A. L., and Kass, D. A. (2006). Tetrahydrobiopterin and cardiovascular disease. Arterioscler. Thromb. Vasc. Biol. 26, 2439-2444.

Moens, A. L., Vrints, C. J., Claeys, M. J., Timmermans, J. P., Champion, H. C., and Kass, D. A. (2008). Mechanisms and potential therapeutic targets for folic acid in cardiovascular disease. Am. J. Physiol. Heart Circ. Physiol. 294, H1971-H977.

Moncada, S., and Higgs, E. A. (2006). The discovery of nitric oxide and its role in vascular biology. Br. J. Pharmacol. 147(Suppl. 1), S193-S201.

Moreau, K. L., Meditz, A., Deane, K. D., and Kohrt, W. M. (2012). Tetrahydrobiopterin improves endothelial function and decreases arterial stiffness in estrogen-deficient postmenopausal women. Am. J. Physiol. Heart Circ. Physiol. 302, H1211H1218.

Muller-Delp, J. M., Spier, S. A., Ramsey, M. W., and Delp, M. D.
(2002). Aging impairs endotheliumdependent vasodilation in rat skeletal muscle arterioles. Am. J. Physiol. Heart Circ. Physiol. 283, H1662H1672.

Mungrue, I. N., Gros, R., You, X., Pirani, A., Azad, A., Csont, T., Schulz, R., Butany, J., Stewart, D. J., and Husain, M. (2002). Cardiomyocyte overexpression of iNOS in mice results in peroxynitrite generation, heart block, and sudden death. J. Clin. Invest. 109, 735-743.

Nakata, S., Tsutsui, M., Shimokawa, H., Yamashita, T., Tanimoto, A., Tasaki, H., Ozumi, K., Sabanai, K., Morishita, T., Suda, O., Hirano, H., Sasaguri, Y., Nakashima, Y., and Yanagihara, N. (2007). Statin treatment upregulates vascular neuronal nitric oxide synthase through Akt/NF-kappaB pathway. Arterioscler. Thromb. Vasc. Biol. 27, 92-98.

Napoli, C., Aldini, G., Wallace, J. L., de Nigris, F., Maffei, R., Abete, P., Bonaduce, D., Condorelli, G., Rengo, F., Sica, V., D’Armiento, F. P., Mignogna, C., de Rosa, G., Condorelli, M., Lerman, L. O., and Ignarro, L. J. (2002). Efficacy and age-related effects of nitric oxide-releasing aspirin on experimental restenosis. Proc. Natl. Acad. Sci. U.S.A. 99, 1689-1694.

Nelson, H. D., Humphrey, L. L., Nygren, P., Teutsch, S. M., and Allan, J. D. (2002). Postmenopausal hormone replacement therapy: scientific review. JAMA 288, 872-881.

Nisoli, E., Tonello, C., Cardile, A., Cozzi, V., Bracale, R., Tedesco, L., Falcone, S., Valerio, A., Cantoni, O., Clementi, E., Moncada, S., and Carruba, M. O. (2005). Calorie restriction promotes mitochondrial biogenesis by inducing the expression of eNOS. Science 310, 314-317.

Novella, S., Dantas, A. P., Segarra, G., Novensa, L., Bueno, C., Heras, M., Hermenegildo, C., and Medina, P. (2010). Gathering of aging and estrogen withdrawal in vascular dysfunction of senescent accelerated mice. Exp. Gerontol. 45, 868-874.

Novella, S., Dantas, A. P., Segarra, G., Novensa, L., Heras, M., Hermenegildo, C., and Medina, P. (2011). Aging enhances contraction to thromboxane $\mathrm{A}(2)$ in aorta from female senescenceaccelerated mice. Age (Dordr.). PMID: 22102320. [Epub ahead of print].

Novensa, L., Novella, S., Medina, P., Segarra, G., Castillo, N., Heras, M., Hermenegildo, C., and Dantas, A. P. (2011). Aging negatively affects estrogens-mediated effects on nitric oxide bioavailability by shifting ERalpha/ERbeta balance in female mice. PLoS ONE 6, e25335. doi:10.1371/journal.pone.0025335

Obeid, R., Kirsch, S. H., Kasoha, M., Eckert, R., and Herrmann, W. (2011). Concentrations of unmetabolized folic acid and primary folate forms in plasma after folic acid treatment in older adults. Metab. Clin. Exp. 60, 673-680.

Pallàs, M., Junyent, F., Verdaguer, E., Beas-Zarate, C., and Camin, A. (2010). Aging control with resveratrol. Drug Discov. Today Ther. Strateg. 7, 51-56.

Peluffo, G., and Radi, R. (2007). Biochemistry of protein tyrosine nitration in cardiovascular pathology. Cardiovasc. Res. 75, 291-302.

Presley, T. D., Morgan, A. R., Bechtold E., Clodfelter, W., Dove, R. W., Jennings, J. M., Kraft, R. A., King, S. B., Laurienti, P. J., Rejeski, W. J., Burdette, J. H., Kim-Shapiro, D. B., and Miller, G. D. (2011). Acute effect of a high nitrate diet on brain perfusion in older adults. Nitric Oxide 24 34-42.

Qiao, X., McConnell, K. R., and Khalil, R. A. (2008). Sex steroids and vascular responses in hypertension and aging. Gend. Med. 5(Suppl. A), S46S64.

Rajapakse, A. G., Yepuri, G., Carvas, J. M., Stein, S., Matter, C. M., Scerri, I., Ruffieux, J., Montani, J. P., Ming, X. F., and Yang, Z. (2011). Hyperactive S6K1 mediates oxidative stress and endothelial dysfunction in aging: inhibition by resveratrol. PLoS ONE 6, e19237. doi:10.1371/journal.pone.0019237

Rodriguez-Manas, L., El-Assar, M., Vallejo, S., Lopez-Doriga, P., Solis, J., Petidier, R., Montes, M., Nevado, J., Castro, M., Gomez-Guerrero, C., Peiro, C., and Sanchez-Ferrer, C. F. (2009). Endothelial dysfunction in aged humans is related with oxidative stress and vascular inflammation. Aging Cell 8, 226-238.

Sabri, M., Ai, J., Marsden, P. A., and MacDonald, R. L. (2011). Simvastatin re-couples dysfunctional endothelial nitric oxide synthase in experimental subarachnoid hemorrhage. PLoS ONE 6, e17062. doi:10.1371/journal.pone.0017062

Santhanam, L., Lim, H. K., Miriel, V., Brown, T., Patel, M., Balanson, S., Ryoo, S., Anderson, M., Irani, K., Khanday, F., Di Costanzo, L. Nyhan, D., Hare, J. M., Christianson, D. W., Rivers, R., Shoukas, A., and Berkowitz, D. E. (2007). Inducible NO synthase dependent S-nitrosylation and activation of arginase 1 contribute to age-related endothelial dysfunction. Circ. Res. 101, 692-702.

Schmitt, C. A., Heiss, E. H., and Dirsch, V. M. (2010). Effect of resveratrol on endothelial cell function: molecular mechanisms. Biofactors 36, 342-349.

Seals, D. R., Jablonski, K. L., and Donato, A. J. (2011). Aging and vascular endothelial function in humans. Clin. Sci. 120, 357-375.

Shepherd, J., Blauw, G. J., Murphy, M. B., Bollen, E. L., Buckley, B. M., Cobbe, S. M., Ford, I., Gaw, A., Hyland, M., Jukema, J. W., Kamper, A. M., MacFarlane, P. W., Meinders, A. E., Norrie, J., Packard, C. J., Perry, I. J., Stott, D. J., Sweeney, B. J., Twomey, C., and Westendorp, R. G. (2002). Pravastatin in elderly individuals at risk of vascular disease (PROSPER): a randomised controlled trial. Lancet 360 1623-1630.

Smith, A. R., Visioli, F., Frei, B., and Hagen, T. M. (2006a). Age-related changes in endothelial nitric oxide synthase phosphorylation and nitric oxide dependent vasodilation: evidence for a novel mechanism involving sphingomyelinase and ceramideactivated phosphatase 2A. Aging Cell 5, 391-400

Smith, A. R., Visioli, F., and Hagen, T. M. (2006b). Plasma membraneassociated endothelial nitric oxide synthase and activity in aging rat aortic vascular endothelia markedly decline with age. Arch. Biochem. Biophys. 454, 100-105.

Smith, C. J., Santhanam, L., Bruning, R. S., Stanhewicz, A., Berkowitz, D. E., and Holowatz, L. A. (2011). Upregulation of inducible nitric oxide synthase contributes to attenuated cutaneous vasodilation in essential hypertensive humans. Hypertension 58, 935-942.

Sobko, T., Marcus, C., Govoni, M., and Kamiya, S. (2010). Dietary nitrate in Japanese traditional foods lowers diastolic blood pressure in healthy volunteers. Nitric Oxide 22, 136-140.

Stice, J. P., Eiserich, J. P., and Knowlton, A. A. (2009). Role of aging versus the loss of estrogens in the reduction in vascular function in female rats. Endocrinology 150, 212-219.

Sun, D., Huang, A., Yan, E. H., Wu, Z., Yan, C., Kaminski, P. M., Oury, T. D., Wolin, M. S., and Kaley, G. (2004). Reduced release of nitric oxide to shear stress in mesenteric arteries of aged rats. Am. J. Physiol. Heart Circ. Physiol. 286, H2249-H2256.

Taddei, S., Virdis, A., Ghiadoni, L., Salvetti, G., Bernini, G., Magagna, A., and Salvetti, A. (2001). Age-related 
reduction of $\mathrm{NO}$ availability and oxidative stress in humans. Hypertension 38, 274-279.

Tamura, K., Yamaguchi, K., and Kogo, H. (2000). 17Beta-estradiol inhibits ovariectomy-induced expression of inducible nitric oxide synthase in rat aorta in vivo. Life Sci. 66, 259-264.

Tian, J., Yan, Z., Wu, Y., Zhang, S. L., Wang, K., Ma, X. R., Guo, L., Wang, J., Zuo, L., Liu, J. Y., Quan, L., and Liu, H. R. (2010). Inhibition of iNOS protects endothelialdependent vasodilation in aged rats. Acta Pharmacol. Sin. 31, 1324-1328.

Timmers, S., Konings, E., Bilet, L., Houtkooper, R. H., van de Weijer, T., Goossens, G. H., Hoeks, J., van der Krieken, S., Ryu, D., Kersten, S., Moonen-Kornips, E., Hesselink, M. K., Kunz, I., SchrauwenHinderling, V. B., Blaak, E. E., Auwerx, J., and Schrauwen, P. (2011). Calorie restriction-like effects of 30 days of resveratrol supplementation on energy metabolism and metabolic profile in obese humans. Cell Metab. 14, 612-622.

Toda, N. (2011). Age-related changes in endothelial function and blood flow regulation. Pharmacol. Ther. 133, 159-176.

Tolbert, T., Thompson, J. A., Bouchard, P., and Oparil, S. (2001). Estrogeninduced vasoprotection is independent of inducible nitric oxide synthase expression: evidence from the mouse carotid artery ligation model. Circulation 104, 2740-2745.

Traish, A. M., Kang, H. P., Saad, F., and Guay, A. T. (2011). Dehydroepiandrosterone (DHEA) - a precursor steroid or an active hormone in human physiology. J. Sex. Med. 8, 2960-2983.

Tsutsui, M., Shimokawa, H., Otsuji, Y., Ueta, Y., Sasaguri, Y., and Yanagihara, N. (2009). Nitric oxide synthases and cardiovascular diseases: insights from genetically modified mice. Circ. J. 73, 986-993.

Ungvari, Z., Csiszar, A., and Kaley, G. (2004). Vascular inflammation in aging. Herz 29, 733-740.

Ungvari, Z., Sonntag, W. E., and Csiszar, A. (2010). Mitochondria and aging in the vascular system. J. Mol. Med. (Berl.) 88, 1021-1027.

Upmacis, R. K., Shen, H., Benguigui, L. E., Lamon, B. D., Deeb, R. S., Hajjar, K. A., and Hajjar, D. P. (2011).
Inducible nitric oxide synthase provides protection against injuryinduced thrombosis in female mice. Am. J. Physiol. Heart Circ. Physiol. 301, H617-H624.

van der Loo, B., Labugger, R., Skepper, J. N., Bachschmid, M., Kilo, J., Powell, J. M., Palacios-Callender, M., Erusalimsky, J. D., Quaschning, T., Malinski, T., Gygi, D., Ullrich, V., and Luscher, T. F. (2000). Enhanced peroxynitrite formation is associated with vascular aging. J. Exp. Med. 192, 1731-1744.

Villanueva, C., and Giulivi, C. (2010). Subcellular and cellular locations of nitric oxide synthase isoforms as determinants of health and disease. Free Radic. Biol. Med. 49, 307-316.

Wagner, A. H., Kohler, T., Ruckschloss, U., Just, I., and Hecker, M. (2000). Improvement of nitric oxidedependent vasodilatation by HMG-CoA reductase inhibitors through attenuation of endothelial superoxide anion formation. Arterioscler. Thromb. Vasc. Biol. 20, 61-69.

Wallerath, T., Deckert, G., Ternes, T., Anderson, H., Li, H., Witte, K., and Forstermann, U. (2002). Resveratrol, a polyphenolic phytoalexin present in red wine, enhances expression and activity of endothelial nitric oxide synthase. Circulation 106, 1652-1658.

Webb, A. J., Patel, N., Loukogeorgakis, S., Okorie, M., Aboud, Z., Misra, S., Rashid, R., Miall, P., Deanfield, J., Benjamin, N., MacAllister, R., Hobbs, A. J., and Ahluwalia, A. (2008). Acute blood pressure lowering, vasoprotective, and antiplatelet properties of dietary nitrate via bioconversion to nitrite. Hypertension 51, 784-790.

Wenzel, P., Daiber, A., Oelze, M., Brandt, M., Closs, E., Xu, J., Thum, T., Bauersachs, J., Ertl, G., Zou, M. H., Forstermann, U., and Munzel, T. (2008). Mechanisms underlying recoupling of eNOS by HMG-CoA reductase inhibition in a rat model of streptozotocin-induced diabetes mellitus. Atherosclerosis 198, 65-76.

Weverling-Rijnsburger, A. W., Blauw, G. J., and Meinders, A. E. (2004). Effect of atorvastatin on impaired vascular function in healthy old men. J. Clin. Pharm. Ther. 29, 157-164.
Whelan, A. P., Sutherland, W. H., McCormick, M. P., Yeoman, D. J., de Jong, S. A., and Williams, M. J. (2004). Effects of white and red wine on endothelial function in subjects with coronary artery disease. Intern. Med. J. 34, 224-228.

Williams, M. R., Dawood, T., Ling, S., Dai, A, Lew, R., Myles, K., Funder, J. W., Sudhir, K., and Komesaroff, P. A. (2004). Dehydroepiandrosterone increases endothelial cell proliferation in vitro and improves endothelial function in vivo by mechanisms independent of androgen and estrogen receptors. J. Clin. Endocrinol. Metab. 89, 4708-4715.

Wong, R. H., Howe, P. R., Buckley, J. D., Coates, A. M., Kunz, I., and Berry, N. M. (2011). Acute resveratrol supplementation improves flow-mediated dilatation in overweight/obese individuals with mildly elevated blood pressure. Nutr. Metab. Cardiovasc. Dis. 21, 851-856.

Wu, S., Ruan, Y., Yin, M., and Lai, W. (2007). Research on the agerelated changes in the nitric oxide pathway in the arteries of rats and the intervention effect of dehydroepiandrosterone. Gerontology 53 234-237.

Xia, N., Daiber, A., Habermeier, A., Closs, E. I., Thum, T., Spanier G., Lu, Q., Oelze, M., Torzewski, M., Lackner, K. J., Munzel, T. Forstermann, U., and Li, H. (2010). Resveratrol reverses endothelial nitric-oxide synthase uncoupling in apolipoprotein $\mathrm{E}$ knockout mice. J. Pharmacol. Exp. Ther. 335, 149-154.

Xing, D., Nozell, S., Chen, Y. F., Hage, F., and Oparil, S. (2009). Estrogen and mechanisms of vascular protection. Arterioscler. Thromb. Vasc. Biol. 29, 289-295.

Yang, B., Larson, D. F., and Watson, R. R. (2004). Modulation of iNOS activity in age-related cardiac dysfunction. Life Sci. 75, 655-667.

Yang, Y. M., Huang, A., Kaley, G., and Sun, D. (2009). eNOS uncoupling and endothelial dysfunction in aged vessels. Am. J. Physiol. Heart Circ. Physiol. 297, H1829-H1836.

Yoon, H. J., Cho, S. W., Ahn, B. W., and Yang, S. Y. (2010). Alterations in the activity and expression of endothelial NO synthase in aged human endothelial cells. Mech. Ageing Dev. 131, 119-123.

Zhang, Y., Janssens, S. P., Wingler, K., Schmidt, H. H., and Moens, A. L. (2011). Modulating endothelial nitric oxide synthase: a new cardiovascular therapeutic strategy. Am. J. Physiol. Heart Circ. Physiol. 301, H634-H646.

Zhang, Z., Wang, M., Xue, S. J., Liu, D. H., and Tang, Y. B. (2012). Simvastatin ameliorates angiotensin II-induced endothelial dysfunction through restoration of Rho-BH4eNOS-NO pathway. Cardiovasc. Drugs Ther. 26, 31-40.

Zhou, Y. H., Tang, J. Y., Wu, M. J., Lu, J., Wei, X., Qin, Y. Y., Wang, C., Xu, J. F., and He, J. (2011). Effect of folic acid supplementation on cardiovascular outcomes: a systematic review and meta-analysis. PLOS ONE 6, e25142. doi:10.1371/journal.pone. 0025142

Zhu, Y., Bian, Z., Lu, P., Karas, R. H., Bao, L., Cox, D., Hodgin, J., Shaul, P. W., Thoren, P., Smithies, O., Gustafsson, J. A., and Mendelsohn, M. E. (2002). Abnormal vascular function and hypertension in mice deficient in estrogen receptor beta. Science 295, 505-508.

Conflict of Interest Statement: The authors declare that the research was conducted in the absence of any commercial or financial relationships that could be construed as a potential conflict of interest.

Received: 04 January 2012; paper pending published: 30 January 2012; accepted: 31 May 2012; published online: 25 June 2012.

Citation: Cau SBA, Carneiro FS and Tostes RC (2012) Differential modulation of nitric oxide synthases in aging: therapeutic opportunities. Front. Physio. 3:218. doi: 10.3389/fphys.2012.00218 This article was submitted to Frontiers in Vascular Physiology, a specialty of Frontiers in Physiology.

Copyright (๑) 2012 Cau, Carneiro and Tostes. This is an open-access article distributed under the terms of the Creative Commons Attribution Non Commercial License, which permits noncommercial use, distribution, and reproduction in other forums, provided the original authors and source are credited. 